\title{
Microstructure, Adhesion and Wear of Plasma Sprayed AlSi-SiC Composite Coatings
}

\author{
Satish Tailor $^{1 *}$, V. K. Sharma ${ }^{1}$, R. M. Mohanty ${ }^{2}$, P. R. Soni ${ }^{1}$ \\ ${ }^{1}$ Department of Metallurgical and Materials Engineering, Malaviya National Institute of Technology, Jaipur, India; ${ }^{2}$ Council of Sci- \\ entific and Industrial Research, CSIR-HQS, New Delhi, India. \\ Email: "taylor.nitj@scientist.com,psmt@rediffmail.com, mohantyrm@yahoo.com
}

Received May $3^{\text {rd }}$, 2012; revised June $7^{\text {th }}$, 2012; accepted June $15^{\text {th }}, 2012$

\begin{abstract}
Al-12.5wt\%Si alloy powder with $15 \mathrm{wt} \% \mathrm{SiC}_{\mathrm{p}}$ was mechanically alloyed (MA) using attrition mill in purified nitrogen atmosphere. The MA processed powder was found to have nano grain size and uniform distribution of $\mathrm{SiC}_{\mathrm{p}}$ in the AlSi matrix. This MA processed powder was used for atmospheric plasma spraying (APS) for varying distances and currents densities. The coatings obtained were studied by image analyzer, SEM and XRD. Microhardness and wear rate of the coatings were evaluated using Vickers indenter and pin on disk type tribometer, respectively. Adhesion strength of the coatings was measured by interfacial indentation test. The results showed that these coatings have uniform distribution of reinforced $\mathrm{SiC}$ particles in the nano crystalline matrix, low porosity (1\% - 2\%), low wear rates and improved adhesion strength. It was also observed that by increasing current density of APS, the adhesive strength increased.
\end{abstract}

Keywords: AlSi-SiC; Attrition Milling; Plasma Spray Coating; Adhesion Strength; Wear Resistance

\section{Introduction}

Plasma spray technology is being widely used for the development of protective coatings to prevent degradation of critical components working under severe conditions. Aatmospheric plasma spraying (APS) is one of these processes based on the creation of a plasma jet to melt a feed stock powder [1]. At the surface of the substrate, particles flatten and solidify rapidly forming a stack of lamellae. Micro-cracks also appear in the microstructure as a consequence of stress accommodation due to the high temperature, rapid solidification and a large difference in thermal expansion coefficients of the substrate and coating. This is especially the case for ceramic coatings deposited on metallic substrates. Plasma sprayed ceramic reinforced coatings, for their higher strength-toweight ratio and superior wear-resistant properties, are preferred in most tribological applications. The suitability of a ceramic reinforced coating on metal substrates depends on 1) the adherence strength at coating-substrate interface; and 2) stability at operating conditions. These coatings provide a dense and hard surface which is resistant to abrasion, corrosion, cavitation, oxidation and erosion.

Plasma sprayed "aluminum based metal matrix" composite coatings are regularly used for wear resistance, thermal barrier applications, aerospace, defence and se-

\footnotetext{
${ }^{*}$ Corresponding author.
}

lected automotive applications such as high performance racing applications [2]. The most commonly used materials as reinforcement are $\mathrm{SiC}, \mathrm{Al}_{2} \mathrm{O}_{3}$ or $\mathrm{B}_{4} \mathrm{C}$ into the aluminum matrix. These materials are used to improve elastic modulus, enhanced heat and wear resistance $[3,4]$.

For dispersoid distribution, the technique of mechaniccal alloying (MA) is widely used [5]. For mechanical alloying attrition mill, which is effectively a high energy ball mill containing internally agitated media [6], is commonly used. The most important characteristic of the attrition mill is that the power input is used directly for agitating the media to achieve alloying/grinding and is not used for rotating or vibrating heavy tank in addition to the media as is the case of vibratory or planetary mill [7]. For each material, there is a minimum grain size that is obtainable by milling. This size is related to the intrinsic properties of the material, such as crystal structure. The minimum grain size seems in a first approximation to be inversely proportional to the melting temperature or bulk modulus [8].

In the present work, mechanical alloyed (MA) AlSi-SiC coatings are deposited on mild steel (MS), stainless steel (SS) and weathering steel (WS; which is also known as Cor-Ten steel) substrates using the APS technique. Plasma sprayed coatings properties like microstructure, crystallite size, deposition efficiency, porosity and hardness were studied. Adhesion strength and wear properties of 
AlSi-SiC coatings were evaluated. An attempt was made to optimize the plasma spray conditions, based on the current density and spray distance to get better coating properties.

\section{Experiment}

Al-12.5wt\%Si alloy aluminium alloy powder (Trade name ALAB supplied by The Metal Powder Company Limited Thirumangalam, India; with a particle size of < $80 \mu \mathrm{m}$ and the Silicon carbide powder with an average particle size of $40 \mu \mathrm{m}$ were used in these investigations. The chemical composition of ALAB alloy is shown in Table 1.

As-received AlSi alloy was mechanically alloyed with $15 \mathrm{wt} \% \mathrm{SiC}_{\mathrm{p}}$ in a high energy attrition mill for $8 \mathrm{hr}$ with a rotation speed of $350 \mathrm{rpm}$. The milling media was hardened steel balls of diameter $12.2 \mathrm{~mm}$. The weight ratio of milling media to powder was 10:1. Acrawax C (1 wt\%) was used as a process control agent. Milling was carried out in purified nitrogen atmosphere to prevent oxidation during milling. The MA processed powder was then degassed at temperature of $200^{\circ} \mathrm{C}$ under a vacuum of $10^{-2}$ torr.

\subsection{Plasma Spraying Conditions}

Atmospheric plasma spraying (APS) was carried out using plasma equipment Sulzer Metco Inc. New York, with $3 \mathrm{M}$ type gun under conditions as presented in Table 2. Coating were applied on three substrates; mild steel (MS), stainless steel (SS) and weathering steel (WS). Prior to spraying, the samples were sand blasted by SiC particles. The plasma coatings were developed on the substrates with different spray distances and current intensities as in (Tables 3 and 4).

Table 1. Chemical composition of ALAB powder.

\begin{tabular}{ccc}
\hline $\begin{array}{c}\text { Aluminum } \\
(\mathrm{wt} \%)\end{array}$ & $\begin{array}{c}\text { Silicon } \\
(\mathrm{wt} \%)\end{array}$ & $\begin{array}{c}\text { Other metallic impurities } \\
(\mathrm{wt} \%)\end{array}$ \\
\hline Balance & $12.5 \%$ & $1 \mathrm{Max}$ \\
\hline
\end{tabular}

Table 2. Plasma spray parameters.

\begin{tabular}{cc}
\hline Parameters & Values \\
\hline Current, $\mathrm{A}$ & $200,300,400,500$ \\
Voltage, $\mathrm{V}$ & 50 \\
$1^{\text {st }}$ gas, Ar, SCFH & 70 \\
$2^{\text {nd }}$ gas $\mathrm{H}_{2}, \mathrm{SCFH}$ & 10 \\
Carrier gas Ar, SCFH & 20 \\
Powder feed rate, RPM & 20 \\
Spray distance, mm & $50,100,150,200$ \\
\hline
\end{tabular}

Table 3. Spraying at fixed current.

\begin{tabular}{ccccc}
\hline \multicolumn{5}{c}{ APS Conditions } \\
\hline Substrates & \multicolumn{4}{c}{ MS, SS, WS } \\
\hline $\begin{array}{c}\text { Condition } \\
\text { Code }\end{array}$ & A1 & A2 & A3 & A4 \\
\hline $\begin{array}{c}\text { Spray Distance } \\
\text { (D), mm } \\
\text { Current, A }\end{array}$ & 50 & 100 & 150 & 200 \\
\hline
\end{tabular}

Table 4. Spraying at fixed distance.

\begin{tabular}{ccccc}
\hline \multicolumn{5}{c}{ APS Conditions } \\
\hline Substrates & \multicolumn{4}{c}{ MS, SS, WS } \\
\hline $\begin{array}{c}\text { Condition } \\
\text { Code }\end{array}$ & B1 & B2 & B3 & B4 \\
\hline $\begin{array}{c}\text { Current, A } \\
\text { Spray Distance } \\
\text { (D), mm }\end{array}$ & 200 & 300 & 400 & 500 \\
\hline
\end{tabular}

\subsection{Characterization}

Morphology of as received and milled powder particles as-sprayed coatings were investigated using a TESCAN scanning electron microscope with energy-dispersive $\mathrm{X}$-ray analyzer (EDAX). The characterization of phases present in the powders and coatings were carried out by Philips X-PERT PRO X-ray diffraction system with $\mathrm{Cu}$ $\mathrm{K} \alpha$ radiation $\left(\mathrm{k}_{\alpha}=0.1542 \mathrm{~nm}\right)$.

Vickers indenter was used to measure the microhardness of coatings at a load of $500 \mathrm{gm}$. Interfacial indentation tests were carried out on coatings using Vickers hardness tester under loads of 0.98, 1.96, 2.94 and $3.92 \mathrm{~N}$ for evaluation of adhesion strength.

The wear behavior of the coatings was carried out under dry-sliding using pin on disk type tribometer for $50 \mathrm{~N}$ applied load. The wear tests were carried out at sliding velocity of $1 \mathrm{~m} / \mathrm{s}$ and sliding distance of $2 \mathrm{~km}$.

\section{Results and Discussion}

Morphology of the as-received powders can be observed in Figure 1. Figure 2(a) shows morphology and particle size distribution in mechanically alloyed $\mathrm{AlSi}_{-} \mathrm{SiC}_{\mathrm{p}}$ composite powder. It can be observed that sub-angular shape of the AlSi powder changes to a sub-rounded and irregular form. The SiC particles are embedded in the matrix powder and uniformly distributed in the finer matrix due to mechanical alloying (Figure 2(b)).

After $8 \mathrm{~h}$ of milling, the mean powder particle size was about $37.13 \mu \mathrm{m}$. The milling process was interrupted at this stage because longer milling time led to finer powder particles that were unsuitable for spraying. A fine particle size causes several problems in APS, including nonuniformity in the powder feed rate and a decrease in powder 

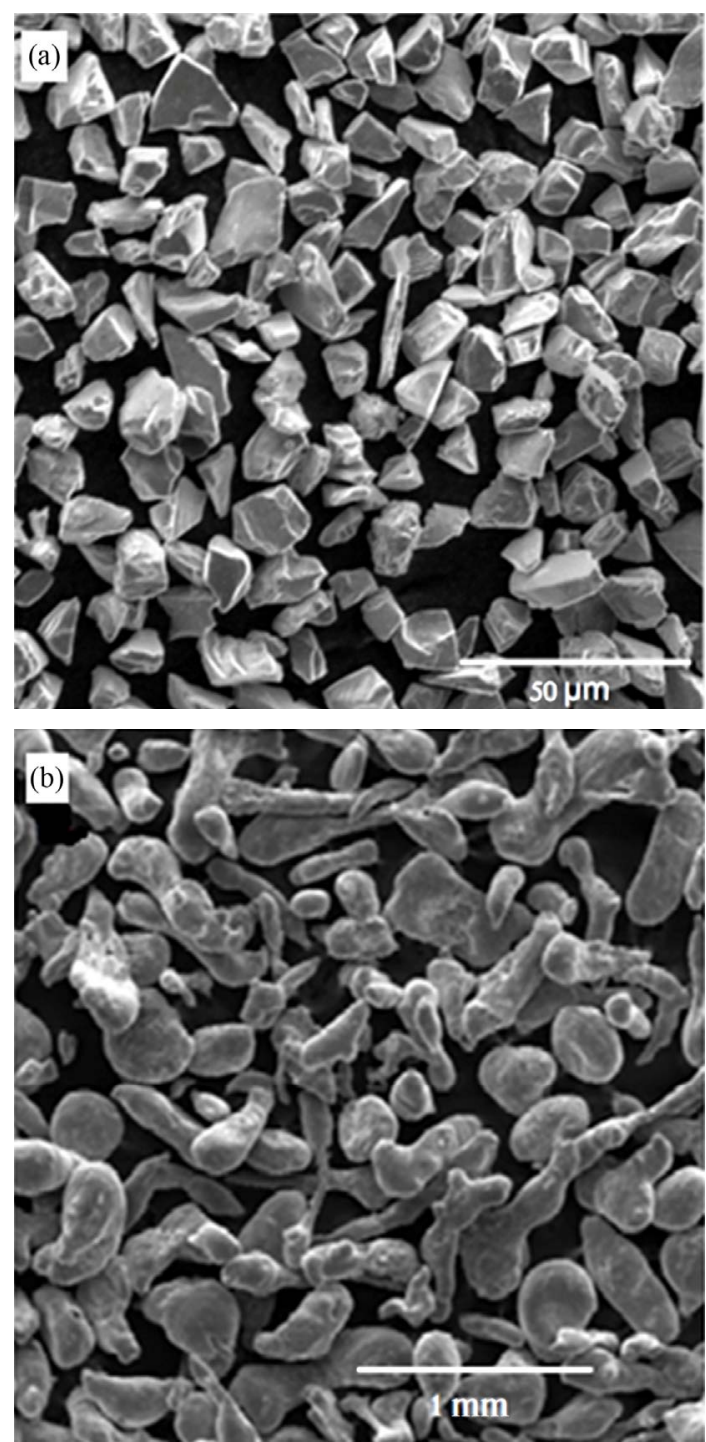

Figure 1. Scanning electron micrograph of as-received powder particles (a) $\mathrm{SiC}$; (b) AISi.

flux, leading to increased porosity and poor adherence [9]. The deposition efficiency of powder on substrates at spray distance (D) of $100 \mathrm{~mm}$ was highest than other spray distance. So, $100 \mathrm{~mm}$ was selected as the optimum spray distances (Table 5). Also by increasing current density of APS, temperature of plasma flame increases, resulting in decrease in porosity content of the coating, due to complete melting of powder particles. It was observed that this composite powder milled for $8 \mathrm{~h}$ gives better coating deposition on substrates for spraying distance (D) of $100 \mathrm{~mm}$ and current (I) of $500 \mathrm{~A}$ (Table 6).

Microstructure of AlSi- $15 \mathrm{wt} \% \mathrm{SiC}_{\mathrm{p}}$ composite coatings on different substrates are shown in Figures $\mathbf{3}$ and $\mathbf{4}$, respectively. $\mathrm{SiC}$ particles exhibit a uniform distribution with about $40 \%, 40 \%-45 \%$ and $45 \%-50 \%$ in the coated surface, on MS, SS and WS respectively, and porosity in the range of $1 \%-2 \%$. Microstructure of the side

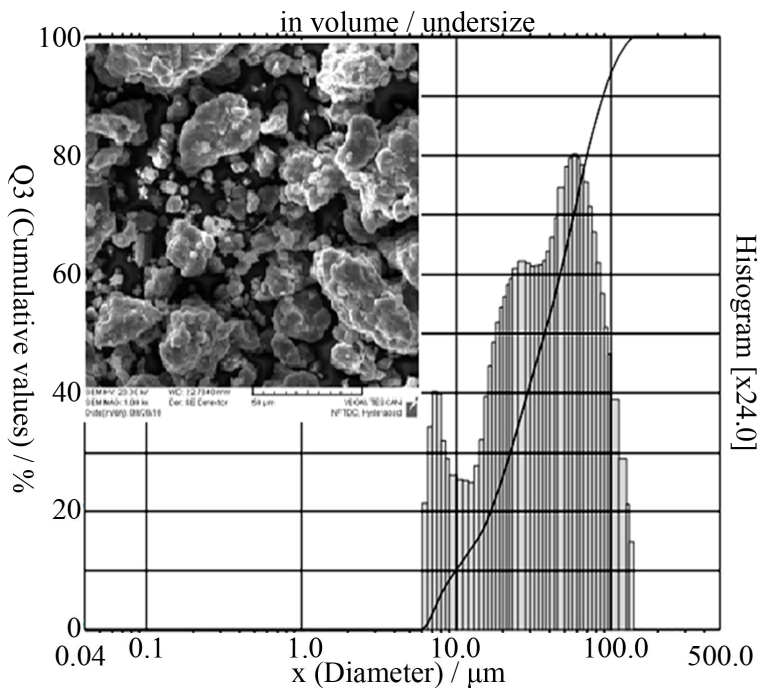

(a)

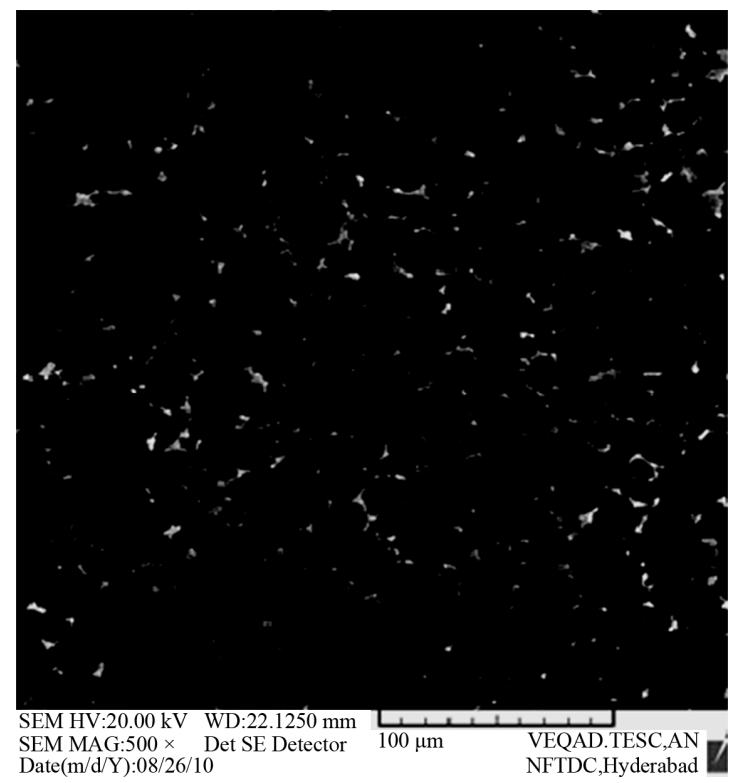

(b)

Figure 2. The powder morphologies: (a) Particle size distribution in MA AISi-SiC powder; (b) Distribution of SiC particles.

Table 5. Substrate weight after plasma spray; at constant current $500 \mathrm{~A}$.

\begin{tabular}{cccc}
\hline \multirow{2}{*}{ Distance (mm) } & \multicolumn{3}{c}{ Sample weight (gm) } \\
\cline { 2 - 4 } & $\begin{array}{c}\text { MS } \\
(36.908)^{*}\end{array}$ & $\begin{array}{c}\text { SS } \\
(49.788)^{*}\end{array}$ & $\begin{array}{c}\text { WS } \\
(90.154)^{*}\end{array}$ \\
\hline 50 & 36.929 & 49.803 & 90.206 \\
100 & 36.994 & 49.857 & 90.240 \\
150 & 36.942 & 49.840 & 90.237 \\
200 & 36.947 & 49.441 & 90.238 \\
\hline
\end{tabular}

* substrate weight before coating. 
Table 6. Substrate weight after plasma spray; at constant spay distance $100 \mathrm{~mm}$.

\begin{tabular}{cccc}
\hline \multirow{2}{*}{ Current (A) } & \multicolumn{3}{c}{ Sample weight (gm) } \\
\cline { 2 - 4 } & MS (36.364) & SS (30.375) & WS (85.260) \\
\hline 500 & 36.480 & 30.540 & 85.441 \\
400 & 36.430 & 30.436 & 85.340 \\
300 & 36.455 & 30.458 & 85.368 \\
200 & 36.471 & 30.338 & 85.336 \\
\hline
\end{tabular}

"substrate weight before coating.

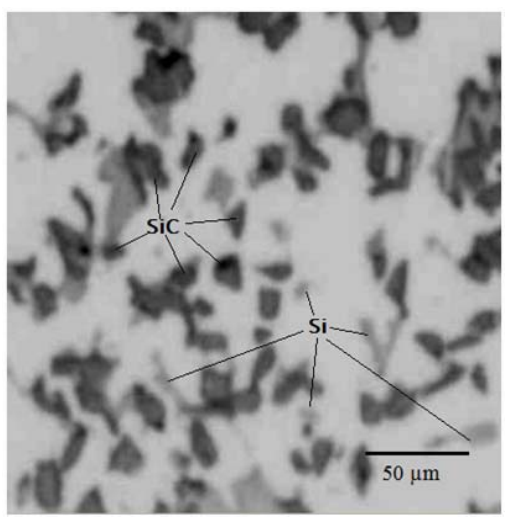

(a)

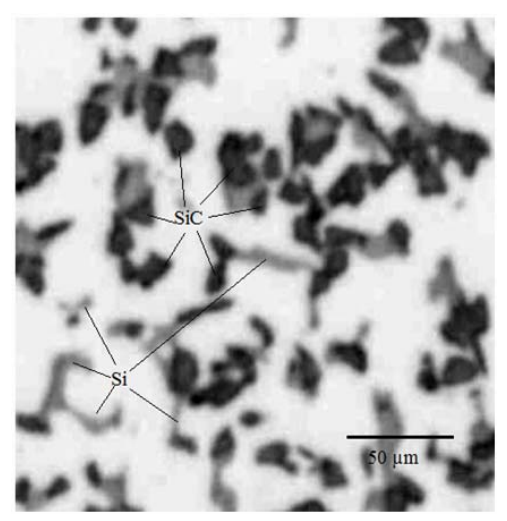

(b)

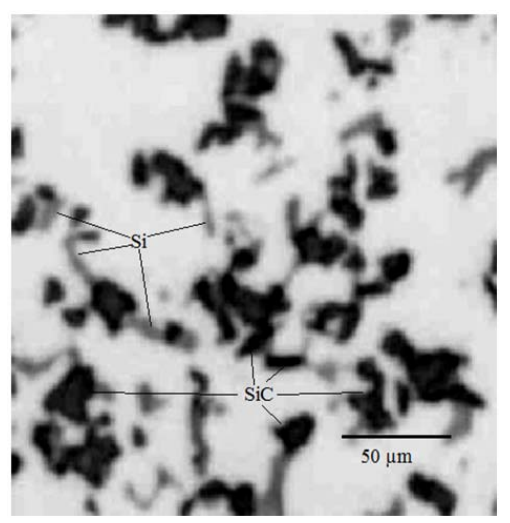

(c)

Figure 3. Microstructure of coating on different substrates; (a) MS; (b) SS; and (c) WS (top view). view of the coatings (Figure 4) show that the interface is free of cracks and the particles are homogeneously dispersed and well integrated inside the matrix.

XRD patterns of APS coatings at optimum conditions have been shown in Figure 5. These XRD patterns show no oxide peaks as well as no new phases. In the plasma

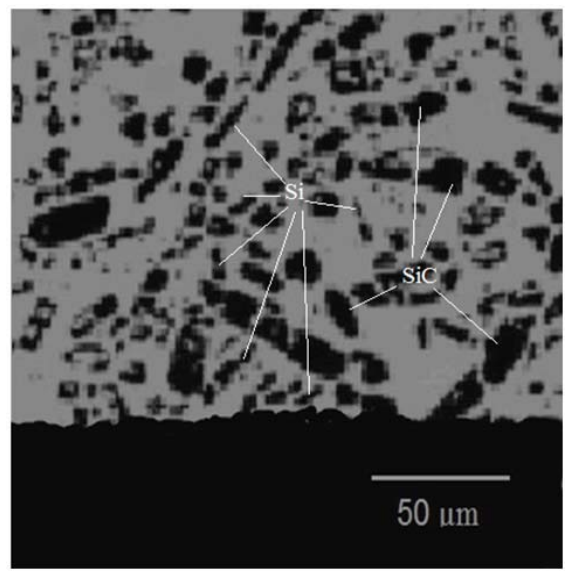

(a)

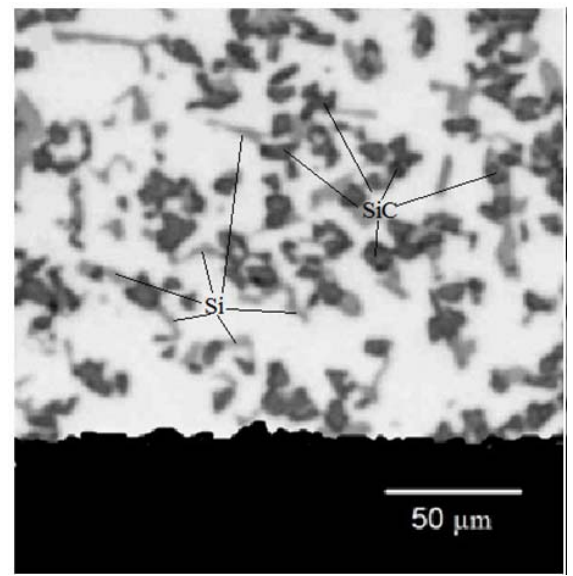

(b)

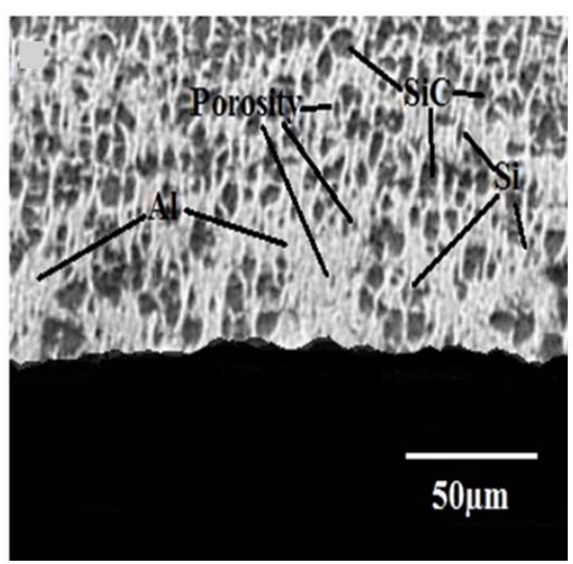

(c)

Figure 4. Microstructure of coating on different substrates; (a) MS; (b) SS; and (c) WS (side view). 
spray coatings, melted particle solidifies with a very high rate (approaching $10^{7} \mathrm{~K} / \mathrm{s}$ ) [10], probably due to that high temperature diffusion and the reaction between the phases present could not take place, and consequently no new phase could form. It should be noted that by increasing spray distance the diffusion time increases, while by increasing current density of APS the plasma temperature increases.

The microhardness and the crystallite size as calculated with the help of XRD patterns by applying Scherrer's relationship [11], are given in the Table 7. It is observed that microhardness in case of WS is higher than the coatings on MS and SS substrates. This can be attributed to higher fraction $(45 \%$ - 50\%) of $\mathrm{SiC}$ particles in the coating and the finer grain size of $15 \mathrm{~nm}$. Crystallite size in the coatings in all three substrate cases is of the order of nanometers. This nano-grain size, high dislocation density due to MA and dispersed oxides and carbides may be the possible sources for high hardness in the coatings [7].

Interfacial indentation tests showed that at a load of $3.92 \mathrm{~N}$, cracks were generated at the interface in B1, B2 and B3 coating conditions (Table 4), while no crack occurred in B4 condition due to the higher spray temperature and higher coating density which lead to higher adhesive strength. Micro-alloying between MA AlSi-SiC powder and substrate at the interface during the spraying also may be the possible cause for the higher adhesion strength.

Figure 6 shows the wear rate of the coatings on different substrates. The composite coatings have significantly improved wear resistance. Coating on WS substrate

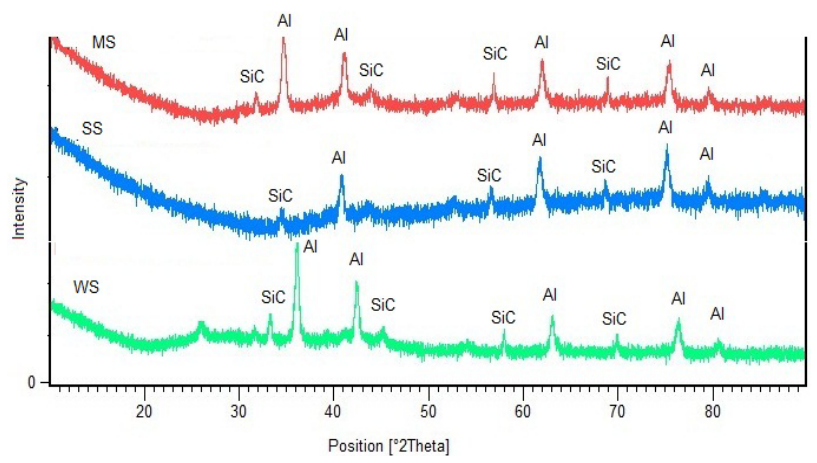

Figure 5. X-ray diffraction patterns of as sprayed coatings at optimum spray conditions.

Table 7. Microhardness and crystallite size in the coatings.

\begin{tabular}{ccc}
\hline Substrate & $\begin{array}{c}\text { Microhardness } \\
(\text { HV) }\end{array}$ & Crystallite Size (nm) \\
\hline MS & 294 & 30 \\
SS & 331 & 25 \\
WS & 351 & 15 \\
\hline
\end{tabular}

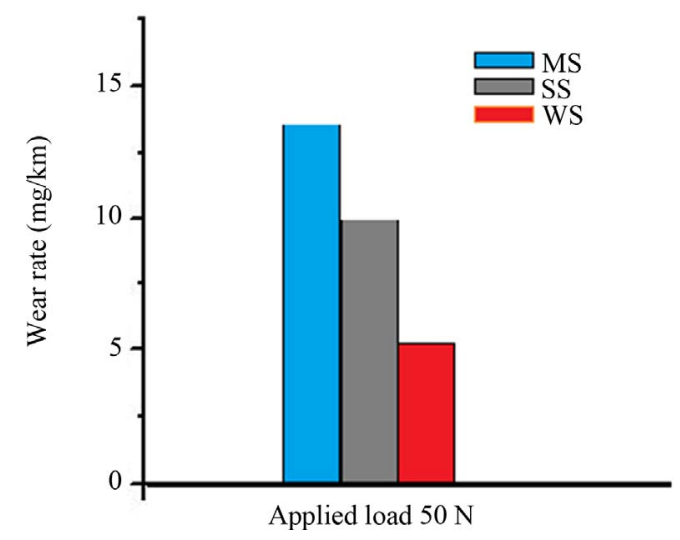

Figure 6. Histogram of the wear rates of the composite coatings at the load of $50 \mathrm{~N}$.

has superior wear resistance due to its higher hardness. Hardness and wear resistance increases with increasing $\mathrm{SiC}$ content, although the relationship is not linear. Venkatraman et al. [12] found that Archard's law is maintained for the Al-SiC system under dry sliding wear conditions. At low SiC contents $(\mathrm{SiC}$ vol\% < 10$)$ the wear rate decreases much faster than the corresponding increase in hardness. The reverse trend was reported by the same authors for higher $\mathrm{SiC}$ content where the increase of $\mathrm{SiC}$ content from 30 to $40 \mathrm{vol} \%$ increased the hardness by $20 \%$ but the wear rates remained the same. Hwang et al. [13] also further observed that the increase in $\mathrm{SiC}$ contents increases the wear resistance.

\section{Conclusions}

MA processed AlSi-15wt $\% \mathrm{SiC}_{\mathrm{p}}$ powder gives good quality atmospheric plasma sprayed coating on mild steel (MS), stainless steel (SS) and weathering steel (WS) substrates. These coatings were found to have homogeneous distribution of $\mathrm{SiC}$ in the matrix of AlSi alloy and the porosity level in the range of $1 \%-2 \%$. Crystallite size in the coatings was found be in order of nano size. Due to these factors coating hardness was high \& wear rate low.

Adhesion crake initation in all three substrate cases was found to be at the load of $3.92 \mathrm{~N}$ or above. Conclusively, it can be said that APS coatings performance is governed by multiple factors like compositions of the coating and the substrate, processing route of the feedstock powder, spraying parameters like current density and spraying distance. For the best results all these parameters should be optimized.

\section{REFERENCES}

[1] L. Pawlowski, "The Science and Engineering of Thermal Spray Coatings,” Wiley, New York, 1995.

[2] R. Mohanty, K. Balasubramanian and S. Seshadri, "Boron 
Carbide-Reinforced Aluminum 1100 Matrix Composites: Fabrication and Properties," Materials Science and Engineering A, Vol. 498, No. 1-2, 2008, pp. 42-52.

[3] M.S. Otsuki, S. Kakehashi and T. Kohno, "Powder Forging of Rapidly Solidified Aluminum Alloy Powders and Mechanical Properties of Their Forged Parts," In: $A d$ vances in Powder Metallurgy, Metal Powder Industries Federation, Princeton, Vol. 2, 1990, pp. 345-349.

[4] G. Madhusudhan Reddy, K. Srinivasa Rao and T. Mohandas, "Friction Surfacing: Novel Technique for Metal Matrix Composite Coating on Aluminium-Silicon Alloy," Surface Engineering, Vol. 25, No. 1, 2009, pp. 25-30. doi:10.1179/174329408X298238

[5] L. Lu, M. O. Lai and C. W. Ng, "Enhanced Mechanical Properties of an Al Based Metal Matrix Composite Prepared Using Mechanical Alloying," Materials Science and Engineering, Vol. 252, No. 2, 1998, pp. 203-211.

[6] R. Sankar and P. Singh, "Synthesis of $7075 \mathrm{Al} / \mathrm{SiC}$ Particulate Composite Powders by Mechanical Alloying," Materials Letters, Vol. 36, No. 1-4, 1998, pp. 201-205. doi:10.1016/S0167-577X(98)00026-3

[7] P. R. Soni, "Mechanical Alloying-Fundamentals \& Applications,” Cambridge International Science Publishing, Cambridge, 2001.
[8] P. Fauchais, G. Montavon and G. Bertrand, "From Powder to Thermally Sprayed Coatings," Journal of Thermal spray Technology, Vol. 19, No. 1-2, 2010, pp. 56-80.

[9] M. A. Clegg, V. Aim and D. J. Silins, "Composite Powder in Thermal Spray Applications," Seventh International Metal Spray Conference, London, 10-14 September 1973, pp. 62-71.

[10] P. Fauchais, A. Vardelle, M. Vardelle, J. F. Coudert and B. Pateyron, "Plasma Spraying and Extractive Metallurgy: Comparisons between Mathematical Modelling and Measurements and between Application and Development," Pure and Applied Chemistry, Vol. 57, No. 9, 1985, pp. 1171-1178. doi:10.1351/pac198557091171

[11] B. D. Cullity, "Elements of X-Ray Diffraction,” AddisonWesley Publishing Company Inc., Boston, 1956, pp. 259261.

[12] B. Venkataraman and G. Sundarajan, “The Sliding Wear Behaviour of Al SiC Particulate Composites-I. Macrobehaviour," Acta Materialia, Vol. 44, No. 2, 1996, pp. 451-460. doi:10.1016/1359-6454(95)00217-0

[13] S. Chung and B. H. Hwang, "A Microstructural Study of the Wear Behaviour of $\mathrm{SiC}_{\mathrm{p}} / \mathrm{Al}$ Composites," Tribology International, Vol. 27, No. 5, 1994, pp. 307-314. doi:10.1016/0301-679X(94)90024-8 